\title{
Psychotic Symptoms in Frontotemporal Dementia: Prevalence and Review
}

\author{
Mario F. Mendez ${ }^{a, b, c}$ Jill S. Shapira ${ }^{a}$ Rochelle J. Woods ${ }^{a, c}$ Eliot A. Licht ${ }^{a, c}$ \\ Ronald E. Saula,c \\ Departments of a Neurology and ${ }^{\mathrm{b}}$ Psychiatry and Biobehavioral Sciences, David Geffen School of Medicine, \\ University of California at Los Angeles, and 'Neurobehavior Unit, VA Greater Los Angeles Healthcare System, \\ Los Angeles, Calif., USA
}

\section{Key Words}

Frontotemporal dementia - Psychosis • Delusions •

Hallucinations $\cdot$ Paranoia $\cdot$ Alzheimer's disease

\begin{abstract}
Background/Aims: Although most patients with frontotemporal dementia (FTD) present with neuropsychiatric symptoms, the frequency of psychotic symptoms is unclear. This study aims to determine the prevalence of psychotic symptoms in a large cohort of well-diagnosed and followed FTD patients compared to age-matched patients with Alzheimer's disease (AD) and to further review the literature on psychosis in FTD. Methods: Delusions, hallucinations and paranoia were evaluated among 86 patients who met consensus criteria for FTD, had frontotemporal changes on functional neuroimaging and were followed for 2 years. They were compared to 23 patients with early-onset AD on a caregiver-administered psychiatric questionnaire. Results: Among the FTD patients, only 2 (2.3\%) had delusions, 1 of whom had paranoid ideation; no FTD patient had hallucinations. This was significantly less than the AD patients, 4 (17.4\%) of whom had delusions and paranoia. Other investigations fail to establish a significant association of psychosis with FTD. Conclusions: These findings, and a literature review, indicate that psychotic symptoms are rare in FTD, possibly due to limited temporal-limbic involvement in this disorder.

Copyright $\odot 2008$ S. Karger AG, Basel
\end{abstract}

\section{KARGER}

Fax +4161306 1234

E-Mail karger@karger.ch

www.karger.com (c) 2008 S. Karger AG, Basel

$1420-8008 / 08 / 0253-0206 \$ 24.50 / 0$

Accessible online at:

www.karger.com/dem

\section{Introduction}

Frontotemporal dementia (FTD) usually presents in middle age with neuropsychiatric symptoms [1, 2]. Alterations in interpersonal conduct and personal regulation are core features of FTD, and many of these patients present to psychiatrists with a suspicion of a primary psychiatric disorder $[3,4]$. The development of disinhibition, socially inappropriate behavior, emotional disengagement, repetitive compulsive-like acts, poor insight and other behavioral changes can lead to a misdiagnosis of FTD as schizophrenia or another psychotic disorder [2-6].

The evidence is indecisive for a specific association of psychosis with FTD, particularly in comparison to other neurodegenerative dementias. There have been case reports, generally without confirmatory neuropathology, which describe delusions, hallucinations or paranoia in patients with possible FTD [7-19]. Other studies describe psychotic symptoms in FTD on informant inventories or questionnaires but do not further define the symptoms [20-24].

There are several problems with prior reports of psychosis in FTD. First, there is variability in the accuracy of their clinical diagnoses of FTD. In the absence of pathology, investigators must rigorously apply clinical criteria in the diagnosis of this disorder. Second, there is variability in the length of follow-up, which can affect the preva-

M.F. Mendez

Neurobehavior Unit (116AF; Bldg 500, 3S)

VA Greater Los Angeles Healthcare, 11301 Wilshire Blvd.

Los Angeles, CA 90073 (USA)

Tel. +1 310478 3711, ext. 42696, Fax +1 310268 4181, E-Mail mmendez@ucla.edu 
lence of psychotic symptoms. Finally, investigators must distinguish significant psychotic symptoms from the often bizarre personality and behavior changes of FTD. This study reports the prevalence of significant psychotic symptoms among a large cohort of well-characterized and followed patients with FTD, compared to agematched patients with Alzheimer's disease (AD), and critically reviews the literature.

\section{Materials and Methods}

\section{Subjects}

All 109 patients in this study presented for evaluation to university-affiliated specialty clinics in dementing disorders. All patients had the insidious onset and progression of behavioral or cognitive changes and were followed up over a 2-year period. These community-based, moderately impaired patients underwent an initial neurobehavioral evaluation, laboratory assessment and magnetic resonance imaging (MRI) of the brain. They were screened for preceding or premorbid mental illnesses and for other medical conditions that could result in psychosis. Finally, as part of the diagnostic evaluation, every patient underwent functional imaging with either single-photon emission tomography (SPECT) or positron emission tomography (PET). Study participation included written informed consent according to institutional review board guidelines for clinical information.

Patients were identified as having the behavioral variant of FTD by consensus criteria [1]. Those with other frontotemporal lobar degenerations, such as primary progressive aphasia and semantic dementia, were excluded. The necessary core features of consensus criteria included evidence of declines in social interpersonal conduct, regulation of personal conduct, emotional expression and insight. This study included 86 patients who continued to meet consensus criteria for FTD after 2 years of follow-up, had frontal or frontotemporal hypoperfusion or hypometabolism, and had not taken antipsychotic medications for more than 3 months for other than psychotic symptoms.

Patients were identified as having $\mathrm{AD}$ by research criteria for clinically probable AD [25]. In order to compare with FTD patients, whose ages of onset were usually in the presenium, the AD patients were included if they had ages of onset of 65 years or younger. Because of this early-onset restriction, this study was able to include only 23 patients who continued to meet criteria for clinically probable AD after 2 years of follow-up, had focal temporoparietal hypoperfusion or hypometabolism, and had not taken antipsychotic medications for more than 3 months for other than psychotic symptoms.

\section{Procedures}

The FTD and AD patients were routinely seen every 6 months and were assessed with the following psychiatric questions. (1) Has he/she had beliefs that others did not share and that are persistently held despite evidence that they are false (in other words, delusions)? (2) Has he/she seen, heard or had experiences that others did not share (in other words, hallucinations)? (3) Has he/ she felt excessively suspicious or persecuted, or believed that someone was trying to hurt him/her (in other words, paranoia)?
Table 1. Patient characteristics: FTD vs. early-onset AD

\begin{tabular}{|c|c|c|}
\hline & FTD & $\mathrm{AD}$ \\
\hline Patients & 86 & 23 \\
\hline \multicolumn{3}{|l|}{ Gender } \\
\hline Male & $44(49)$ & $10(43)$ \\
\hline Female & $42(51)$ & $13(57)$ \\
\hline Education, years & $14.91 \pm 4.22$ & $15.19 \pm 2.91$ \\
\hline Age at onset, years & $56.70 \pm 11.12$ & $61.2 \pm 9.92$ \\
\hline Age at presentation, years & $58.41 \pm 10.50$ & $63.52 \pm 9.49$ \\
\hline Duration at 2 years FU, years & $4.82 \pm 3.34$ & $5.23 \pm 4.24$ \\
\hline MMSE on presentation & $25.01 \pm 6.21$ & $23.59 \pm 5.42$ \\
\hline MMSE at 2 years FU & $22.32 \pm 6.44$ & $20.91 \pm 6.14$ \\
\hline CDR on presentation & $1.49 \pm 1.01$ & $1.33 \pm 1.41$ \\
\hline $\mathrm{CDR}$ at 2 years $\mathrm{FU}$ & $1.99 \pm 1.48$ & $2.11 \pm 1.12$ \\
\hline Delusions score $\mathrm{e}^{1,2}$ & $0.40 \pm 0.96$ & $1.11 \pm 1.69$ \\
\hline Hallucinations score ${ }^{1}$ & $0.19 \pm 0.56$ & $0.45 \pm 1.12$ \\
\hline Paranoia score ${ }^{1,3}$ & $0.17 \pm 0.61$ & $1.22 \pm 1.79$ \\
\hline
\end{tabular}

Values are means \pm SD. Figures in parentheses represent percentages. $\mathrm{FU}=$ Follow-up.

${ }^{1}$ Likert scale scores for presence of symptoms at any point from onset up to 2 years of follow-up.

${ }^{2}$ Significant group differences: $\mathrm{t}=2.53$, d.f. $=107, \mathrm{p}<0.05$.

${ }^{3}$ Significant group differences: $\mathrm{t}=4.37$, d.f. $=107, \mathrm{p}<0.001$.

The clinic neurologists administered the questions after an interview with the patient's informant or caregiver. The investigators coded the psychiatric items on a 5-point Likert scale from 'not at all characteristic' to 'extremely characteristic.' After 2 years of follow-up, the presence of psychotic symptoms at any point in the course was judged significantly present if they attained Likert scores of 3 or more (moderately or extremely characteristic). Group differences were compared using 2-tailed $t$ tests and $\chi^{2}$ analysis as appropriate.

\section{Results}

The FTD and AD groups did not differ on demographic and dementia severity variables such as the MiniMental State Examination (MMSE) and the Clinical Dementia Rating (CDR) Scale (see table 1) [26, 27]. There were no differences in the overall stages of their disease; both groups were evaluated during early to middle stages of progression.

The 2 dementia groups differed significantly on prevalence of psychotic symptoms. The overall Likert scores for delusions and paranoia were significantly different between the 2 groups (see table 1). From disease onset to the end of the 2 -year period of follow-up, only $2(2.3 \%)$ FTD patients had delusions, compared to $4(17.4 \%)$ of the 
$\operatorname{AD}$ group $\left(\chi^{2}=5.29 ; p<0.05\right)$. The persistently held false beliefs of the 2 FTD patients were: (1) being married to different movie stars at different times, and (2) the belief that her husband was dedicated to treating her poorly. Both of these delusions were investigated and found to be false.

All 4 of the AD patients had paranoid delusions, particularly spousal infidelity. One of the 2 FTD patients with delusions had paranoia, compared to all 4 of the AD patients with delusions. Hallucinations occurred in 1 additional patient in each dementia group. There were no correlations between the Likert scores for the 3 psychotic symptoms and the demographic or dementia severity (MMSE or CDR) variables. No clear pattern emerged suggesting correlation with other behavioral symptoms except that the $\mathrm{AD}$ patients had more memory deficits by definition than the FTD patients. Possibly significant is the fact that the one FTD patient with delusions and paranoia also had prominent memory difficulty.

\section{Discussion}

Clinicians often attribute psychotic symptoms to FTD. This report, however, does not document a specific tendency for delusions, hallucinations or paranoid ideation among a large cohort of patients who met clinical criteria for FTD and who were followed for 2 years. This is the first report expressly dedicated to evaluating psychotic symptoms among FTD patients. This study's findings are discussed in the context of a critical review of the medical literature.

Although FTD may resemble schizophrenia [28-31], many reports of FTD patients with delusions or hallucinations probably referred to alternative diagnoses. The original report was Goldstein and Katz's [7] (1937) analysis of the psychopathology of a 56-year-old woman with presumed Pick's disease. She had visual hallucinations and delusions of seeing her recently deceased brother, expressed agitation and distress over his 'going hungry' and had marked intellectual deterioration. A careful review of her history, however, suggested a psychotic depression precipitated by her brother's death or the presence of another neuropsychiatric disorder rather than FTD. Neary et al. [10] (1988) described 1 of 7 FTD patients with paranoid ideas, and Miller et al. [11] (1991) reported 1 of 8 FTD patients with the delusion that he was a messenger of God. This last patient, however, proved to have a left basal ganglia lacunar infarction and hypoperfusion in both parietal regions suggestive of AD. Similarly, Miller et al.
[12] (1993) described a 60-year-old depressed woman with possible FTD who complained that a dentist had inserted radioactive material into her mouth causing her teeth to crack and abscess, but she too had severe bilateral parietal hypoperfusion. Vanderzeypen et al. [17] (2003) claimed that a 34-year-old man with psychotic symptoms might have FTD, but the patient had an abnormal neurological examination and a normal PET scan. Finally, Kerssens et al. [18] (2006) reported a 65-year-old woman with depression, personality changes and bizarre delusions with acoustic, haptic and gustatory hallucinations, but her other symptoms and course were more suggestive of psychotic depression than of FTD.

A further review of other case reports failed to establish an association of psychotic symptoms with FTD. Waddington et al. [13] (1995) described a 65-year-old woman with a schizophrenia-like psychosis who developed increasing cognitive deficits and the neuropathological hallmarks of Pick's disease on brain biopsy. She had begun with a personality change at the age of 25 and could have had a coincident association of 2 diseases. Kitabayashi et al. [14] (2005) had a similar patient with psychosis at the age of 24 and dementia from about the age of 62. Lamote et al. [15] (1998) described a 35-year-old woman with neuroimaging suggesting FTD who was diagnosed as having 'schizophrenic psychosis of the hebephrenic type', but she did not have delusions or hallucinations. Dell and Halford [16] (2002) reported a 37year-old woman who, 10 months postpartum, began talking to pictures, counting ceiling tiles, naming inanimate objects and having 'odd thoughts', and had disproportionate frontal lobe atrophy on MRI. Despite marked loosening of associations, however, psychotic features were not reliably elicited.

There were 2 additional case reports that were reasonably convincing for a clinical course consistent with FTD with psychotic symptoms, but neither had pathological confirmation of the diagnosis. The first was a 56-year-old woman who developed depression and the false belief of having contracted AIDS from her husband [12, 32]. Her SPECT showed frontotemporal hypoperfusion, worse on the right than left. The second was a 53-year-old man who presented with hallucinations, both visual and auditory, and had frontotemporal atrophy on MRI and frontal hypometabolism on PET [19].

The more extensive FTD patient series did not include a full description of the psychotic symptoms. Among frontal variant FTD patients, investigators reported delusions and hallucinations in 5 and $2 \%$ of 68 patients and in 15 and $8 \%$ of 23 patients, respectively, without further 
description or follow-up [33, 34]. In contrast, other series failed to find any psychosis among well-characterized patients with FTD $[5,35,36]$. On the Neuropsychiatric Inventory [37], informants have reported delusions in 5 and hallucinations in $0-3$ patients from groups of 22 and 23 FTD patients (frontal or behavioral variant) [20, 21]. Although the number of delusions among the FTD patients was still fewer than among those with AD [20], it may still have been an overestimation. Informant responses on the Neuropsychiatric Inventory delusion question ('Does the patient have beliefs that you know are not true?') required clarification. For example, in a report of delusions among $8(12.7 \%)$ of 63 FTD patients [24], none of these patients had true delusions after the informants' responses had been further clarified. Other investigators have documented few delusions among FTD patients in comparison to $\mathrm{AD}$ patients, whereas delusions and paranoia were common in the middle stages of $\mathrm{AD}[22,23,38]$. Finally, 3 clinicopathological series with definitive frontotemporal lobar degeneration on autopsy found no psychosis among 19 patients [4], no hallucinations among 48 patients [39] and only 1 clearly defined paranoid-hallucinatory state among 20 patients $[8,9]$.

The infrequency of delusions, hallucinations or paranoia in FTD, particularly as compared to $\mathrm{AD}$, is important for what it reveals about brain mechanisms of psychosis. In $\mathrm{AD}$, delusions are worse with poor memory and cognitive function and are associated with frontal hypofunction, particularly on the right [40,41]. Lesions in the right frontal cortex may facilitate delusions through poor mapping of internal feelings, such as paranoia, on observed reality, and inappropriate correction of any subsequent inaccurate conclusions and beliefs [42]. This conclusion is supported by the correlation of delusions in $\mathrm{AD}$ with the density of neurofibrillary tangles in midfrontal gyrus and other neocortical regions [43]. AD patients with psychotic symptoms, however, also have involvement of the mesiotemporal area [44, 45]. Lesions in the mesiotemporal area may result in de- lusions that involve fear or a disturbed sense of threat or familiarity through disruption of limbic functions that link perception to emotional states [42]. FTD patients, in contrast to $\mathrm{AD}$ patients, have relative sparing of the temporal limbic system [46]. On the other hand, some FTD patients may have psychotic-like symptoms related to their compulsive tendencies or to coincident low $\mathrm{B}_{12}$ levels [47].

There are several potential limitations of this study. First, there was no pathological confirmation. The FTD patients, however, met consensus criteria for FTD, had corroborative functional neuroimaging results, and were followed and monitored for 2 years. Second, the number of patients with significant psychotic symptoms was small. This study, however, aimed for greater specificity of the psychotic symptoms in order to distinguish them from the often bizarre personality and behavioral changes of FTD. Third, the number of patients with AD was also small. The number of AD patients was limited because of the need to have similar ages of onset and followup periods among $\mathrm{AD}$ patients in the same clinical program. Fourth, the one FTD patient with delusions and paranoia also had significant memory difficulty. She nevertheless met consensus criteria for FTD and had relatively isolated frontal hypometabolism on PET. Ultimately, a frontal variant of early-onset AD could not be ruled out in this patient.

In conclusion, the relative paucity of psychotic symptoms in FTD has several implications. First, there are important implications for differential diagnosis. In the past, as many as $21 \%$ of autopsy-verified FTD patients have been misdiagnosed with psychosis or schizophrenia [4]. Second, the findings in this report support minimizing the use of antipsychotic medications, particularly given an increased risk of neuroleptic side effects in FTD [48, 49]. Third, the lack of psychosis in FTD may indicate that the temporal-limbic system is necessary to develop unchecked paranoid false beliefs, as in AD. Further work is required in order to corroborate these findings, particularly among FTD patients followed to autopsy.

\section{References}

Psychotic Symptoms in Frontotemporal Dementia
Dement Geriatr Cogn Disord 2008;25:206-211 
cial consequences in frontotemporal dementia. Alzheimer Dis Assoc Disord 2005; 19(suppl 1):S15-S18.

5 Gregory CA, Hodges JR: Clinical features of frontal lobe dementia in comparison to $\mathrm{Alz}$ heimer's disease. J Neural Transm Suppl 1996;47:103-123.

6 Kertesz A: Pick Complex: an integrative approach to frontotemporal dementia: primary progressive aphasia, corticobasal degeneration, and progressive supranuclear palsy. Neurologist 2003;9:311-317.

7 Goldstein K, Katz SE: The psychopathology of Pick's disease. Arch Neurol Psychiatry 1937;38:473-490

8 Gustafson L: Clinical picture of frontal lobe degeneration of non-Alzheimer type. Dementia 1993;4:143-148.

$\checkmark 9$ Gustafson L: Frontal lobe degeneration of non-Alzheimer type. II. Clinical picture and differential diagnosis. Arch Gerontol Geriatr 1987;6:209-223.

10 Neary D, Snowden JS, Northen B, Goulding P: Dementia of frontal lobe type. J Neurol Neurosurg Psychiatry 1988;51:353-361.

-11 Miller BL, Cummings JL, Villanueva-Meyer J, Boone K, Mehringer CM, Lesser IM, Mena I: Frontal lobe degeneration: clinical, neuropsychological and SPECT characteristics. Neurology 1991;41:1374-1382.

-12 Miller BL, Chang L, Mena I, Boone K, Lesser IM: Progressive right frontotemporal degeneration: clinical, neuropsychological and SPECT characteristics. Dementia 1993;4: 204-213.

13 Waddington JL, Youssef HA, Farrell MA, Toland J: Initial schizophrenia-like psychosis in Pick's disease: case study with neuroimaging and neuropathology, and implications for frontotemporal dysfunction in schizophrenia. Schizophr Res 1995;18:7982 .

- 14 Kitabayashi Y, Otakara C, Hirosawa R, Narumoto J, Fukui K: Frontotemporal dementia complicated with schizophrenia. Psychiatry Clin Neurosci 2005;59:749-750.

15 Lamote H, Tan KL, Verhoeven WM: Frontotemporale dementie bij een jonge vrouw met ogenschijnlijk schizofrenie. Ned Tijdschr Geneeskd 1998;142:1962-1965.

-16 Dell DL, Halford JJ: Dementia presenting as postpartum depression. Obstet Gynecol 2002;99:925-928.

-17 Vanderzeypen F, Bier JC, Genevrois C, Mendlewicz J, Lotstra F: Démence frontale ou 'démence précoce'? A propos del'observation d'un trouble psychotique associé à une détérioration sévère. Encephale 2003;29:172180.

- 18 Kerssens CJ, Pijnenburg YA, Schouws S, Eikelenboom P, van Tilburg W: Het ontstaan van psychotische verschijnselen op latere leeftijd: laat onstane schizofrenie of frontotemporale dementia? Tijdschr Psychiatr 2006;48:739-744.
19 Reischle E, Sturm K, Schuierer G, Ibach B: Ein Fall von schizophrenieformer Störung bei frontotemporaler Demenz (FTD). Psychiatr Prax 2003;30(suppl 2):S78-S82.

20 Levy ML, Miller BL, Cummings JL, Fairbanks LA, Craig A: Alzheimer disease and frontotemporal dementias: behavioral distinctions. Arch Neurol 1996;53:687-690.

21 Liu W, Miller BL, Kramer JH, Rankin K, Wyss-Coray C, Gearhart R, Phengrasamy L, Weiner M, Rosen HJ: Behavioral disorders in the frontal and temporal variants of frontotemporal dementia. Neurology 2004;62:742748 .

22 Lopez OL GM, Becker JT, Reynolds CF, Sudilovsky A, DeKosky ST: Symptoms of depression and psychosis in Alzheimer's disease and frontotemporal dementia. Neuropsychiatry Neuropsychol Behav Neurol 1996;9:154-161.

23 Hirono N, Mori E, Tanimukai S, Kazui H, Hashimoto M, Hanihara T, Imamura T: Distinctive neurobehavioral features among neurodegenerative dementias. J Neuropsychiatry Clin Neurosci 1999;11:498-503.

24 Mourik JC, Rosso SM, Niermeijer MF, Duivenvoorden $H J$, van Swieten JC, Tibben A: Frontotemporal dementia: behavioral symptoms and caregiver distress. Dement Geriatr Cogn Disord 2004;18:299-306.

25 McKhann G, Drachman D, Folstein M, Katzman R, Price D, Stadlan EM: Clinical diagnosis of Alzheimer's disease: report of the NINCDS-ADRDA Work Group under the auspices of the Department of Health and Human Services Task Force on Alzheimer's Disease. Neurology 1984;34:939-944.

26 Folstein MF, Folstein SE, McHugh PR: 'MiniMental State': a practical method for grading the cognitive state of patients for the clinician. J Psychiatr Res 1975;12:189-198.

27 Hughes CP, Berg L, Danzinger WL, Coben LA, Martin RL: A new clinical scale for the staging of dementia. Br J Psychiatry 1982; 140:566-572.

-28 McKhann GM, Albert MS, Grossman M, Miller B, Dickson D, Trojanowski JQ, Work Group on Frontotemporal Dementia and Pick's Disease: Clinical and pathological diagnosis of frontotemporal dementia: report of the Work Group on Frontotemporal Dementia and Pick's Disease. Arch Neurol 2001;58:1803-1809.

29 Stone J, Griffiths TD, Rastogi S, Perry RH, Cleland PG: Non-Picks frontotemporal dementia imitating schizophrenia in a 22 -yearold man. J Neurol 2003;250:369-370.

30 Jansen Steur EN: Frontotemporale dementie bij een jonge vrouw met ogenschijnlijk schizofrenie. Ned Tijdschr Geneeskd 1998; 142:1962-1965.

31 Diehl J, Kurz A: Frontotemporal dementia: patient characteristics, cognition, and behaviour. Int J Geriatr Psychiatry 2002;17: 914-918.
2 Edwards-Lee T, Miller BL, Benson DF, Cummings JL, Russell GL, Boone K, Mena I: The temporal variant of frontotemporal dementia. Brain 1997;120:1027-1040.

33 Bozeat S, Gregory CA, Ralph MA, Hodges JR: Which neuropsychiatric and behavioural features distinguish frontal and temporal variants of frontotemporal dementia from Alzheimer's disease? J Neurol Neurosurg Psychiatry 2000;69:178-186.

34 Le Ber I, Guedj E, Gabelle A, et al: Demographic, neurological and behavioural characteristics and brain perfusion SPECT in frontal variant of frontotemporal dementia. Brain 2006;129:3051-3065

35 Mendez MF, McMurtray A, Chen AK, Shapira JS, Mishkin F, Miller BL: Functional neuroimaging and presenting psychiatric features in frontotemporal dementia. J Neurol Neurosurg Psychiatry 2006;77:4-7.

36 Gregory CA: Frontal variant of frontotemporal dementia: a cross-sectional and longitudinal study of neuropsychiatric features. Psychol Med 1999;29:1205-1217.

37 Cummings JL, Mega M, Gray K, RosenbergThompson S, Carusi DA, Gornbein J: The Neuropsychiatric Inventory: comprehensive assessment of psychopathology in dementia. Neurology 1994;44:2308-2314.

- 38 Engelborghs S, Maertens K, Nagels G, Vloeberghs E, Marien P, Symons A, Ketels V, Estercam S, Somers N, De Deyn PP: Neuropsychiatric symptoms of dementia: crosssectional analysis from a prospective, longitudinalBelgian study. Int J Geriatr Psychiatry 2005;20:1028-1037.

39 Liscic RM, Storandt M, Cairns NJ, Morris JC: Clinical and psychometric distinction of frontotemporal and Alzheimer dementias. Arch Neurol 2007;64:535-540.

40 Schneider LS, Dagerman KS: Psychosis of Alzheimer's disease: clinical characteristics and history. J Psychiatr Res 2004;38:105111.

41 Sultzer DL, Brown C, Mandelkern MA, Mahler ME, Mendez MF, Chen ST, Cummings JL: Delusional thoughts and regional frontal/temporal cortex metabolism in Alzheimer's disease. Am J Psychiatry 2003; 160:341-349.

42 Richardson ED, Malloy PF: The frontal lobes and content-specific delusions; in Salloway SP, Malloy PF, Duffy JD (eds): The Frontal Lobes and Neuropsychiatric Illness. Washington, American Psychiatric Press, 2001, pp 215-232.

-43 Farber NB, Rubin EH, Newcomer JW, Kinscherf DA, Miller JP, Morris JC, Olney JW, McKeel DW Jr: Increased neocortical neurofibrillary tangle density in subjects with Alzheimer disease and psychosis. Arch Gen Psychiatry 2000;57:1165-1173. 
44 Mentis MJ, Weinstein EA, Horwitz B, McIntosh AR, Pietrini P, Alexander GE, Furey M, Murphy DGM: Abnormal brain glucose metabolism in the delusional misidentification syndromes: a positron emission tomography study in Alzheimer disease. Biol Psychiatry 1995;38:438-449.

-45 Lopez OL, Smith G, Becker JT, Meltzer CC, DeKosky ST: The psychotic phenomenon in probable Alzheimer's disease: a positron emission tomography study. J Neuropsychiatry Clin Neurosci 2001;13:50-55.
6 Rosen HJ, Gorno-Tempini ML, Goldman WP, Perry RJ, Schuff N, Weiner M, Feiwell R, Kramer JH, Miller BL: Patterns of brain atrophy in frontotemporal dementia and semantic dementia. Neurology 2002;58:198208.

47 Engelborghs S, Maertens K, Marien P, Vloeberghs E, Somers N, Nagels G, De Deyn PP: Behavioural and neuropsychological correlates of frontal lobe features in dementia. Psychol Med 2006;36:1173-1182.
48 Mendez MF, Lipton A: Emergent neuroleptic hypersensitivity as a herald of presenile dementia. J Neuropsychiatry Clin Neurosci 2001;13:347-356.

49 Pijnenburg YA, Sampson EL, Harvey RJ, Fox NC, Rossor MN: Vulnerability to neuroleptic side effects in frontotemporal lobar degeneration. Int J Geriatr Psychiatry 2003;18: $67-72$. 